Arch. Histol. Cytol., Vol. 59, No. 1 (1996)

p. $71-78$

\title{
Mesangial Cells of the Lamprey, Lampetra japonica, Store Vitamin $A^{*}$
}

\author{
Peter BAUER** and Kenjiro WAKE \\ Department of Anatomy, Tokyo Medical and Dental University School of Medicine, Tokyo, Japan
}

Received October 18, 1995

\begin{abstract}
Summary. Structure and vitamin A-storage of the mesangial cells in the lamprey kidney are documented using the gold chloride method, fluorescence histochemistry and electron microscopy. Abundant lipid droplets in the cytoplasm of the mesangial cells release intense, but quickly fading vitamin A-fluorescence under a fluorescence microscope and react with gold chloride. Characteristic tubular invaginations of the plasma membrane which usually occur in the lamprey smooth muscle cells are observed in these cells. We discuss similarities of the lamprey mesangial cells with hepatic stellate cells in the lamprey and mammals, such as vitamin A-storage, blood flow-regulation and proliferative potential. To the best of our knowledge, this is the first report on and proof of vitamin A-storage in mesangial cells, providing evidence for a vitamin A-storing cell lineage in vertebrates.
\end{abstract}

Mesangial cells are of special interest because they are strategically well positioned advantageously in the mesangium, i.e., the connective tissue which is carried into the renal glomerulus. These cells provide structural support to the glomerular tuft. Contraction underlies the regulation of blood flow of the capillaries and the glomerular filtration by generating vasoactive substances (AUSIELlo et al., 1980; KREISBERG, 1983; FOIDART and MAHIEU, 1986; BRENNER et al., 1986; SAKAI and KRIZ, 1987; SADOVNIC et al., 1991). These cells also play a role in renewing the basal lamina by phagocytosis (SADOVNIC et al., 1991; FAWCETT, 1994). Although the mesangial cells are considered as a special type either of pericytes or myofibroblasts, a common definition of them is still missing. We have chosen the lamprey for investigation because of its richness in vitamin A. Vitamin A-storage is one of the main characteristics of fibroblast-like cells (KoMURO, 1990). In order to learn more about fibroblast-like cells, we focused on cytological features of mesangial cells as important representatives of this diverse cell population and compared them to other major fibroblast-like cells.

In the present study we tried to carefully credit morphological and functional perspectives of the lamprey mesangial cells. We found surprisingly abundant vitamin A-containing lipid droplets in the cytoplasm of these cells, a feature which, together with further evidence, relates them to the hepatic stellate and smooth muscle cells of the lamprey.

\section{METERIALS AND METHODS}

Adult lampreys, Lampetra japonica, were caught during their spawning-upstream migration in December in the rivers of Hokkaido, Japan. With reference to the criteria defined by HARDISTY and POTTER (1977) they were classified as stage VII in the life cycle of the anadromous parasitic lamprey. We obtained eight animals from a professional lamprey dealer in Tokyo, transported them alive to the department and immediately used them for experimentation.

Under anaesthesia with phenobarbital, kidneys were

\footnotetext{
*This paper is dedicated to Professor Dr. Tsuneo FuJiTA, Niigata University, Japan, on the occasion of his retirement in March 1995. This research was supported by Research Grants-in-Aid from the Ministry of Education, Science, Sports and Culture, Japan, to K.W. (No. 2454110, No. 05454134).

**A fellow of the Mercedes Benz-McKinsey-scholarship program for German-Japanese exchange provided by the Deutsche Studienstiftung, Bonn, Germany.
} 


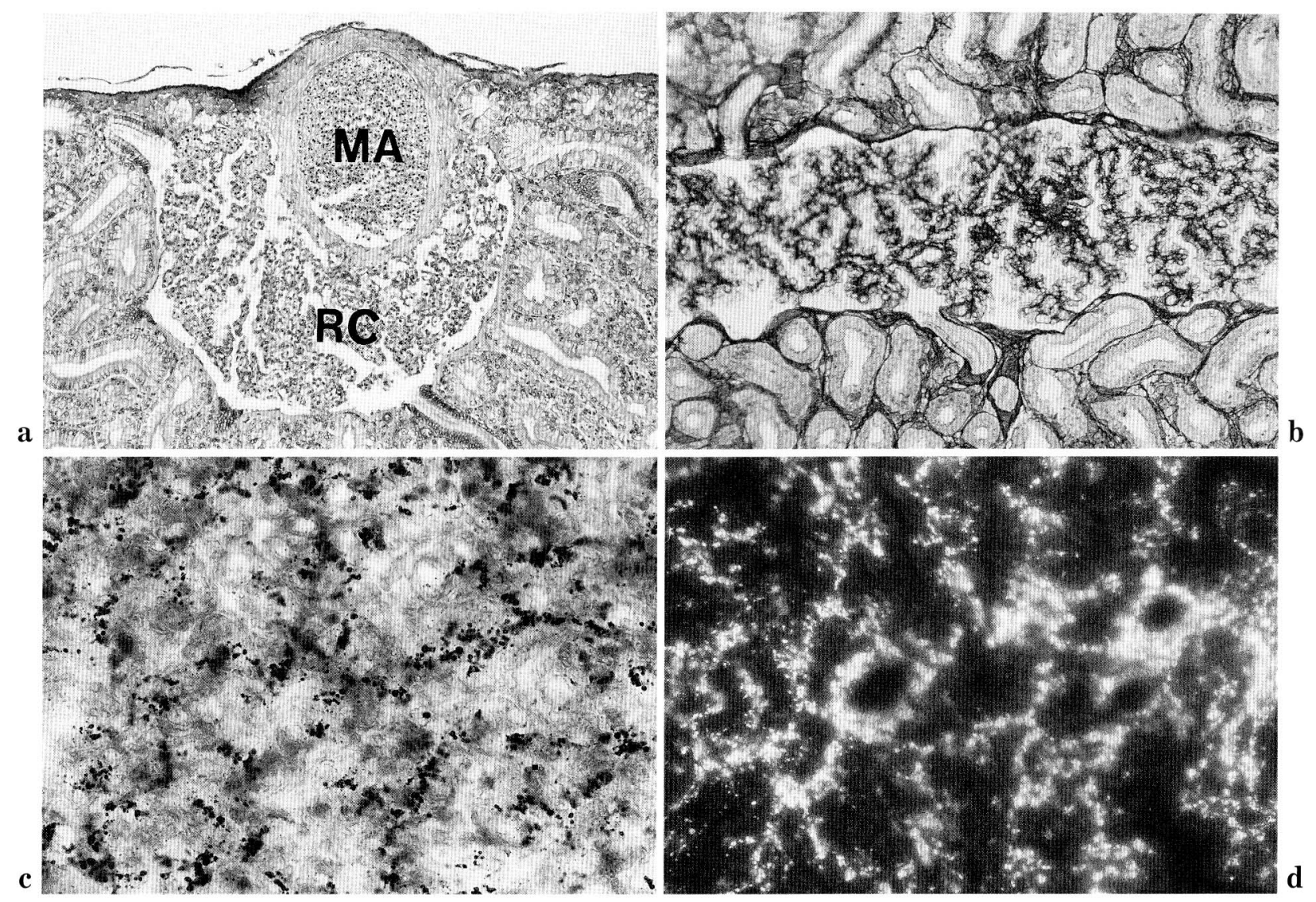

Fig. 1 a. A transverse section of a renal corpuscle $(R C)$ of adult Lampetra japonica. $M A$ medial artery. Hematoxylin-eosin, $\times 50$. b. Silver impregnation method clearly revealing the widely spanning network of argyrophil reticular fibers which encompass the capillaries of the renal corpuscle. $\times 35$. c. Vitamin A-containing lipid droplets are shown in form of black spots against a red background. These gold precipitates are not scattered randomly but spread in a grid-like fashion accompanying reticular fibers shown in b. Kupffer's gold chloride method. $\times 130$. d. Intense vitamin A-autofluorescence from the renal corpuscle quickly fades away after irradiation with ultraviolet light. The fluorescence sources correspond with the gold chloride reaction (c) throughout the renal corpuscle. $\times 130$

perfused with phosphate-buffered saline (PBS 0.1 M, $\mathrm{pH}$ 7.4) and consecutively 4\% paraformaldehyde (PFA) through the open end of the dorsal aorta. For routine staining the tissue blocks were immersed in neutral 10\% formalin for over one week, dehydrated and embedded in paraffin. Paraffin sections were also stained with a modification of Bielschowsky's silver impregnation method (ISHII and ISHII, 1965).

\section{Gold chloride method}

Freshly obtained kidney blocks were fixed in $0.05 \%$ chromic acid for 0.5 to $2 \mathrm{~h}$ and cut to a $40-50 \mu \mathrm{m}$ thickness on a freezing microtome, immersed once more again in $0.05 \%$ chromic acid solution for $10 \mathrm{~min}$ and directly transferred unwashed to the gold stain- ing solution (KUPFFER, 1876; WAKE et al., 1986). Individual sections were deposited at the bottom of the jar and thus exposed to the decessive staining step. All this was done at room temperature. The gold staining solution consisted of $1 \mathrm{ml} 1 \%$ gold chloride, $1 \mathrm{ml} \mathrm{1 \%} \mathrm{HCl}$ and $98 \mathrm{ml}$ distilled water ready made immediately before use. The stained sections were put into an incubator adjusted to $20^{\circ} \mathrm{C}$ for 12 to $16 \mathrm{~h}$, washed in distilled water, dehydrated through graded alcohol and finally mounted in balsam.

\section{Fluorescence microscopy}

Tissue blocks were fixed in $10 \%$ formol for 12 to $24 \mathrm{~h}$ at $4^{\circ} \mathrm{C}$ and cut to a thickness $10 \mu \mathrm{m}$ by a freezing microtome, mounted in water and immediately observed under 


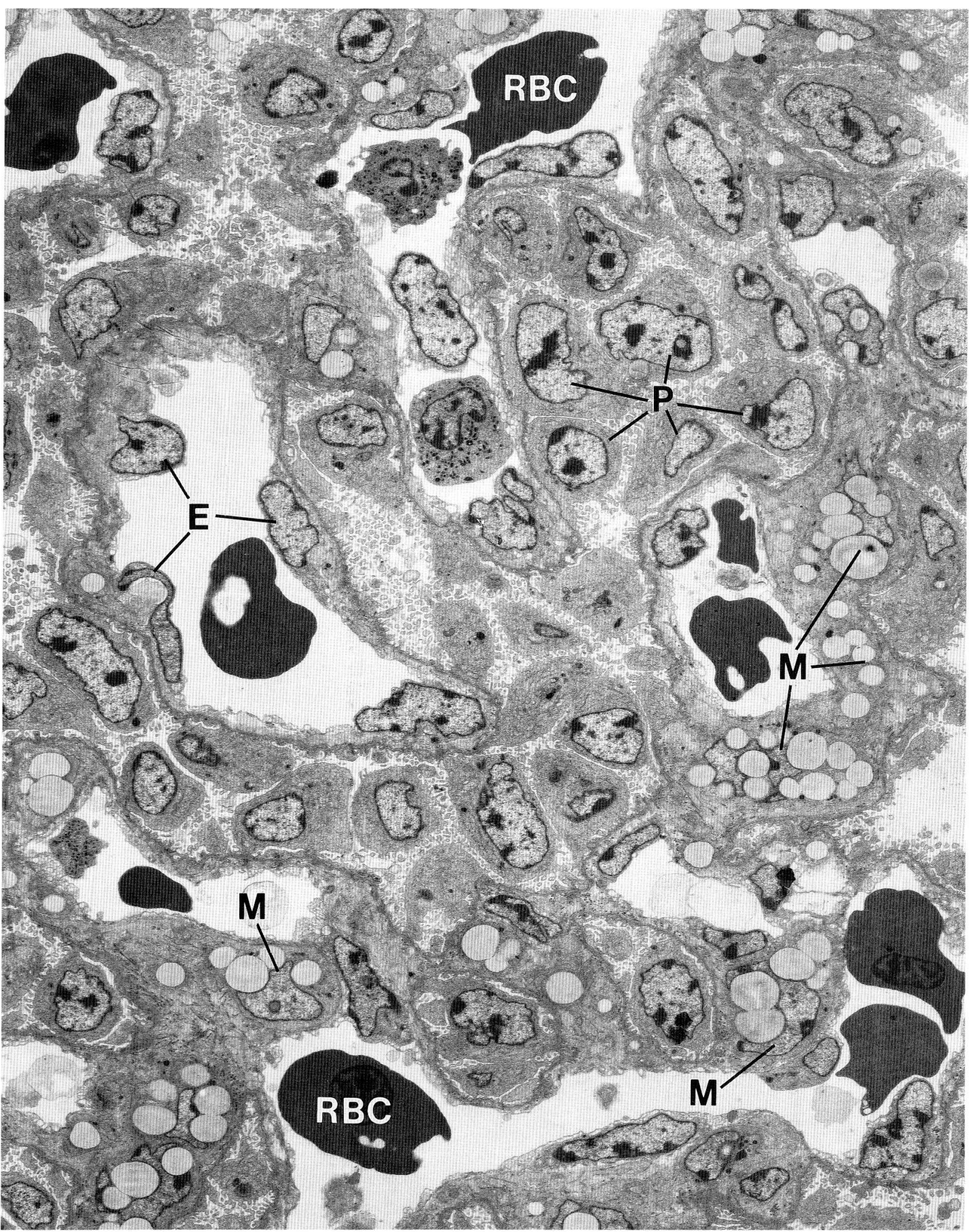

Fig. 2. Electron micrograph of a part of the renal corpuscle of the lamprey showing the presence of lipid droplets in the cytoplasm of the mesangial cells $(M)$. These cells are sandwiched between the podocytes $(P)$ on one side and the capillary endothelial cells $(E)$ on the other. $R B C$ red blood corpuscle. $\times 2,400$ 


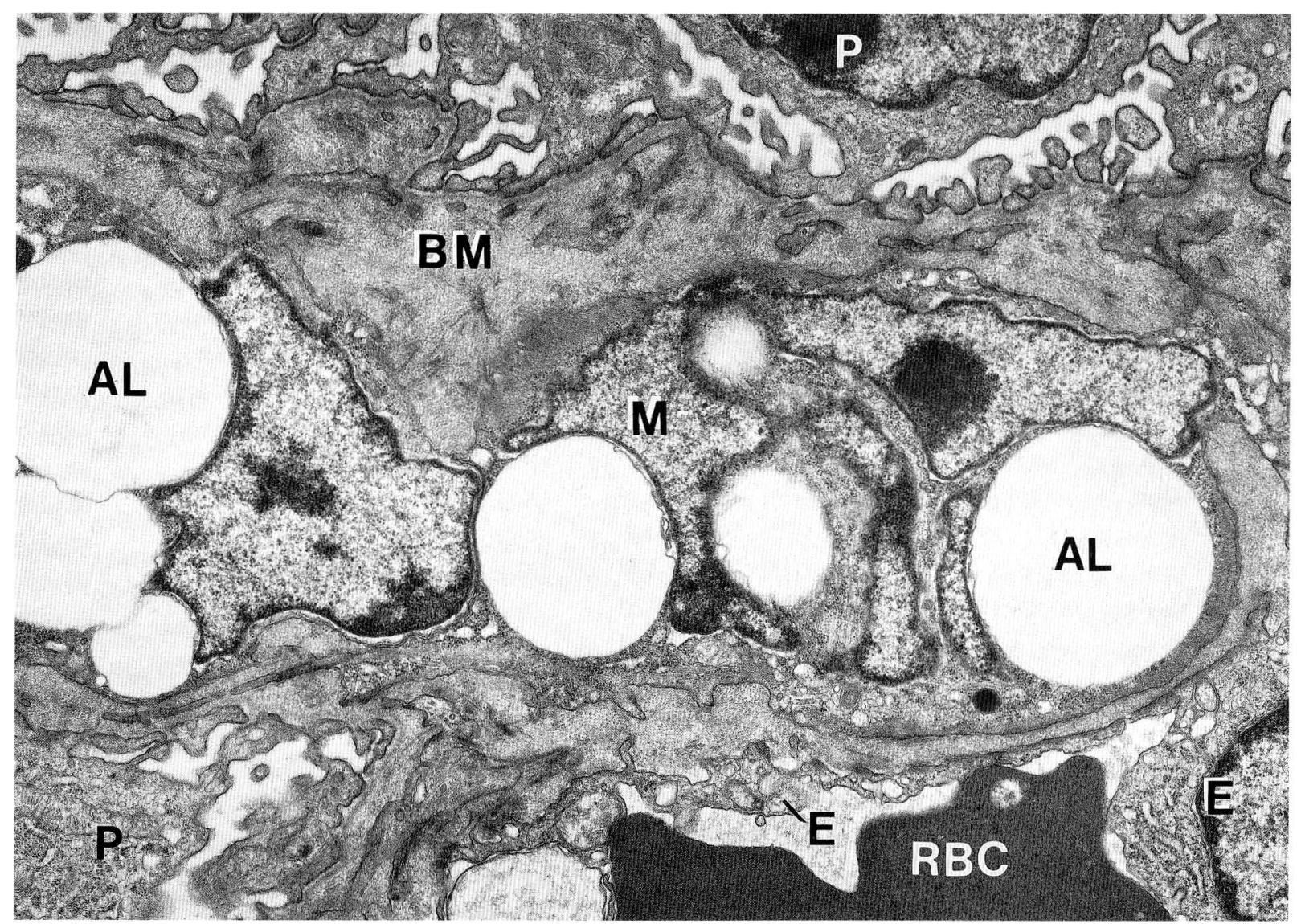

Fig. 3. Higher magnification of a mesangial cell $(M)$ with lipid droplets $(A L)$ containing vitamin $\mathrm{A}$ by which the nucleus is deeply indented and thus irregular in shape. $B M$ basement membrane, $E$ endothelial cell, $P$ podocyte, $R B C$ red blood corpuscle. $\times 15,000$

a fluorescence microscope (Olympus Vanox, equipped with Model AH-RFL-LB) using a U (UGL) excitation filter and a U (DM 400+L 420) or V (DM 455+Y 455) filter for emission. Especially for fluorescence photomicrography, a Tri-X pan (Kodak, ASA 400) film was selected and developed with a Konidol Super developer (Sakura) for $9 \mathrm{~min}$ at $18^{\circ} \mathrm{C}$.

\section{Electron microscopy}

The kidneys were fixed by perfusion via the open distal end of the dorsal aorta using a syringe fitted with a needle, serving a fixative agents consisted of 1.5\% glutaraldehyde, $0.65 \%$ cacodylate buffer ( $\mathrm{pH} 7.4$ ) and $0.6 \%$ sucrose. Postfixation of the small blocks was carried out in 1\% phosphate-buffered osmium tetroxide $(\mathrm{pH}$ 7.4), dehydrated and embedded in Poly/Bed 812. The sections were double stained and examined with a JEOL-200CX electron microscope operated at $200 \mathrm{kV}$.

\section{RESULTS}

\section{Light microscopy}

The histological structure of the adult lamprey kidney differs considerably from that of other vertebrates (see MrYoshi, 1978; Youson, 1981). The most characteristic feature is the presence of a large compound renal corpuscle which is composed of a single glomus (Fig. 1a, b). The glomus is lobulated and each lobule consists of several loops of capillaries. The lobules are surrounded by a Bowman's capsule. The silver impregnation method clearly reveals a widely spanning network of argyrophil reticular fibers around the capillaries and the Bowman's capsule (Fig. 1b). By use of the gold chloride method, granular deposits of reduced gold are seen distributed in a grid-like fashion accompanying the reticular fibers (Fig. 1c). Under a fluorescence microscope, intense but quickly fading vitamin A fluorescence is released from the 

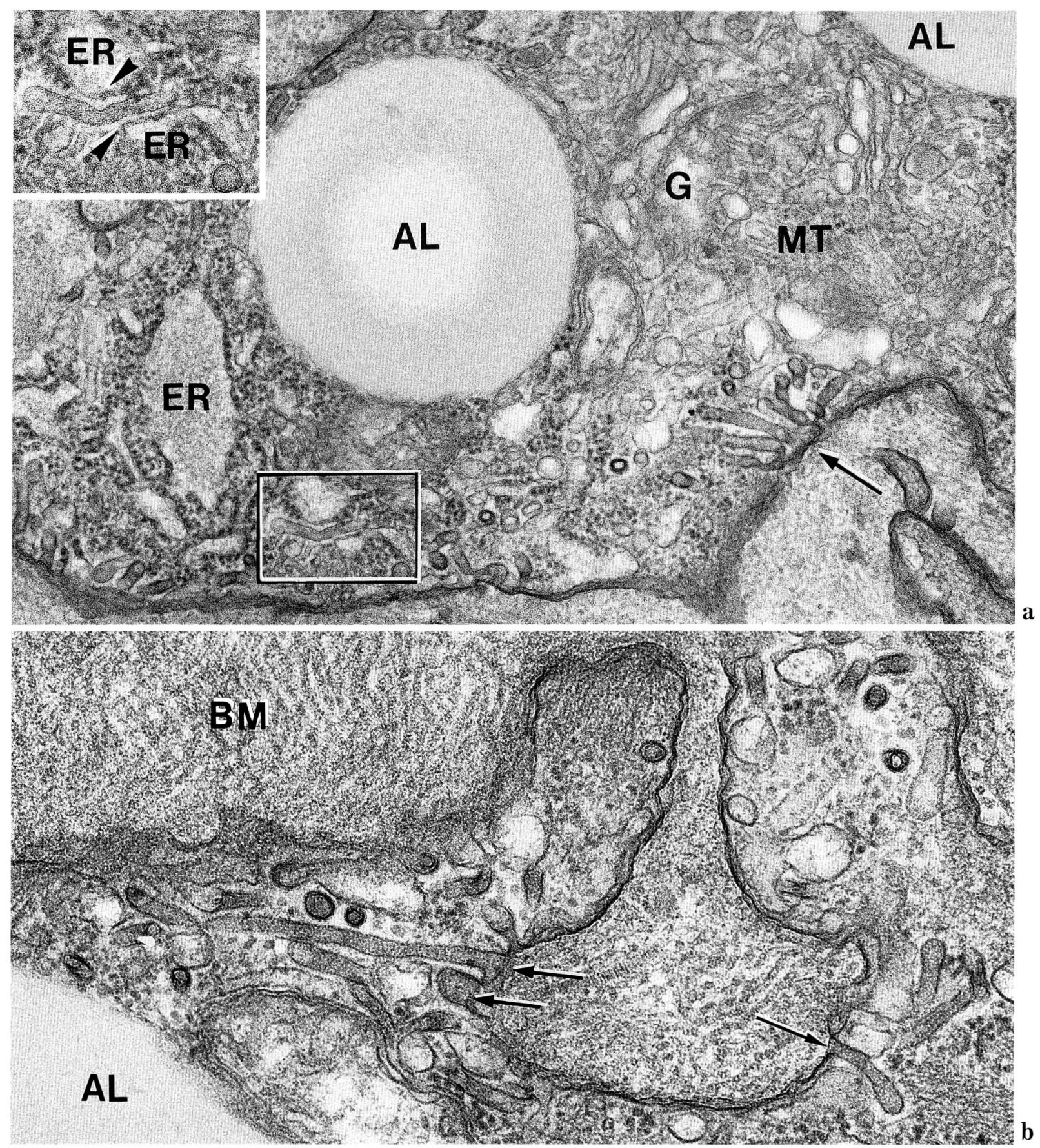

Fig. 4 a. Showing the cell organellae of the mesangial cells. Granular endoplasmic reticulum (ER) and Golgi complex $(G)$ are well developed. The cisterns of the $E R$ contain filamentous material. Characteristic tubular structures are seen in subplasmalemmal region (arrow). Inset. Smooth-endoplasmic reticular membranes (arrow heads) are closely associated with the tubular membranes. $A L$ vitamin A-containing lipid droplets, MT microtubuli. $\times 49,000$, inset: $\times 78,000$. b. The tubular membranes, at the one end, connect with the plasma membrane (arrows). AL lipid droplets, $B M$ basement membrane. $\times 64,000$ 


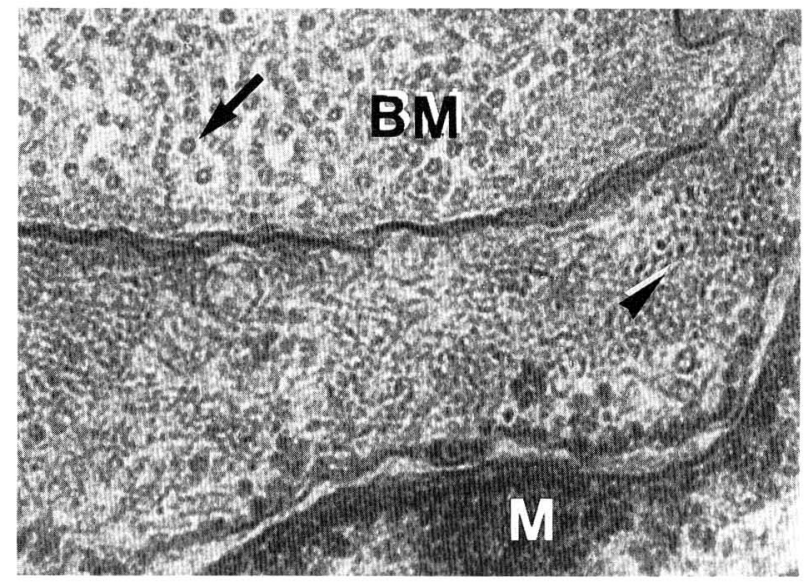

Fig. 5. Abundant cytoplasmic filaments (arrowhead) are present in the cytoplasm of the mesangial cell $(M)$. Basement membrane $(B M)$ consisting of fine tubular filaments (arrow). $\times 64,000$

renal corpuscle (Fig. 1d). The localization of gold deposits and the fluorescent sources coincide exactly.

\section{Electron microscopy}

Electron microscopy definitely revealed the presence of lipid droplets in the cytoplasm of the mesangial cells, characterized by their location in the mesangium - which is separated from podocytes and capillary endothelial cells by a thick basement membrane (Figs. 2, 3). The mesengial cells are irregular in shape and their nuclei are deeply indented by large lipid droplets in the cytoplasm. Most of the lipid droplets are not surrounded by the unit membrane, i.e. type II vitamin A-containing lipid droplets (WAKE, 1974). The cytoplasm contains rough-surfaced endoplasmic reticulum and a Golgi complex (Fig. 4a). Lipid droplets were found neither in the endothelial cells nor in the podocytes. The cisterns of the rough-surfaced endoplasmic reticulum contain flocculate material. Characteristic tubular structures, approximately 60 $\mathrm{nm}$ in diameter, are frequently observed in the subsurface area of the cells (Fig. 4a, b). The outer end of the tubular structure opens to the extracellular space (Fig. 4b), and the deeper part is closed to the smoothsurfaced endoplasmic reticulum (Fig. $4 \mathrm{a}$, inset). Numerous microtubules are seen in the vicinity of the Golgi area (Fig. 4a). Cytoplasmic microfilaments (6 $\mathrm{nm}$ in thickness) converge towards the plasma membrane (Fig. 5). The extracellular matrix consists of abundant microfibrils and a small number of collagen fibrils (Figs. 4a, b, 5).

\section{DISCUSSION}

Mesangial cells are generally characterized as myofibroblasts or pericytes (DRENCKHAHN et al., 1990; WALDHERR et al., 1992). Immunohistochemically mammalian mesangial cells have been shown to be positive for, among other mesenchymal cell markers, vimentin, alpha smooth muscle actin (WALDHERR, ditto) and desmin (SADovnic et al., 1991). They provide structural support for capillary loops and modulate filtration by their smooth muscle activity. Mesangial cells are able to generate vasoactive agents and to synthesize and break down structural elements such as intercellular matrix components and other macromolecules. Furthermore, they are production and target site for regulators of cell proliferation in addition to modulating glomerular injury (SCHLONDORFF, 1987). Some researchers address the mesangial cell as a pericyte. There is morphological evidence for this point of view: YAMANAKA (1988) stressed the connection of the mesangial cell to "the vascular pericytesmooth muscle cell system". JoHnSon et al. (1992), emphasize that the mesangial cell may acquire characteristics of myofibroblasts of other tissues. Trying to re-evaluate fibroblasts and fibroblast-like cells, KomURo (1990) proposed to categorize the connective tissue cells into subtypes depending on their main functions: 1) fibrogenesis; 2) tissue skeleton or barrier; 3) intercellular communication system; 4) gentle contractile machinery; 5) endocrine activity; and 6) vitamin A-storage, adding that differences among these cells are quantitative rather than qualitative and that it is therefore almost impossible to set clear-cut criteria for distinguishing genuine fibroblasts from a large population of fibroblast-like cells. Such does not only hold true for the large population of connective tissue cells in general, but also for the mesangial cells focussed on in this work.

We were able here to provide data elucidating the contractile machinery of the lamprey mesangial cells and their potential to store abundant vitamin A. KUDO (1938), utilizing a fluorescence microscope, reported the existence of vitamin A-containing cells in the kidneys (see WAKE, 1980). Works were published dealing with the possible existence of 'a vitamin A-storing cell system' (YAMADA and HirosAWA, 1976) and 'vitamin A-uptake cells' (Kusumoto and FujiTA, 1976) distributed in the extrahepatic organs. The latter for the first time denoted Sudan III-positive cells in the renal capsule, interstitial tissue and in the mesangium of the glomerulus. These authors suggested those vitamin A-storing cells were identical with or at least closely related to the hepatic stellate cells, and with 
their broad study they were able to show the wide distribution of these cells in tissues of mesenchymal origin, especially in the reticular tissues. Based on these findings we have been able to go beyond the organ and tissue level and clearly demonstrate the vitamin A within the cytoplasm of the mesangial cells, strongly supporting these authors' views.

An even strong vitamin A-response is emitted from the splanchnic connective tissue of the lamprey (WAKE, 1982). This enables us to understand the great potential of lampreys to store vitamin A. In the lamprey mesangial cells, vitamin A is stored within lipid droplets of type II (WAKE, 1974), that is, non-membranebound. Type I, or membrane-bound lipid droplets, are so rare that we suggest them to be a transient, developing site for storing vitamin $\mathrm{A}$ and conclude that with such a massive amount of vitamin A given, the maximal capacity of storage is reached and thus only lipid droplets of type II may be found.

Tubular structures were observed in the subplasmalemmal region of the lamprey mesangial cells. These tubular structures are also well developed in the smooth muscle cells of the lamprey (WAKE and SENOO, 1986; HATAE et al., 1994). They are further found in the hepatic stellate cells (WAKE and SENOO, 1986; WAKE et al., 1987), and other mesenchymal cells such as fibroblasts and endothelial cells of the artery (HATAE et al., 1994). HATAE et al. suggested that the surface depolarization is transmitted inwardly to cause the release of calcium from the sarcoplasmic reticulum because these tubular structures are in close contact with the sarcoplasmic reticulum of the lamprey smooth muscles. Thus these tubules may be regarded as a primitive type of T-system of the muscle fibers. We found those tubules in the lamprey mesangial cells, too, closely contacted the smooth endoplasmic reticulum. In this connection, the mesangial cells of the lamprey may be contractile. The fact that these cells contain abundant cytoplasmic filaments supports the above speculation. With this contribution, we continue a series of studies aimed to provide further evidence for a stellate cell lineage (WAKE, 1982; WAKE et al., 1989). We have been able to clearly demonstrate the storage of vitamin $\mathrm{A}$ in the mesangial cells of a vertebrate species, a function that dominates many cell types (such as the hepatic stellate cells) of mesenchymal origin in the splanchnic organs of vertebrates. We obtained convincing evidence for the existence of a connected cell system that consists of hepatic stellate cells and a group of cells defined morphologically. This tentatively proffers the idea of an 'endothelial-smooth muscle cell axis' (WAKE and SENOO, 1986). Within this spectrum, hepatic stellate cells, pillar cells of the gill filaments (WAKE et al., 1989), pericytes, myofibroblasts and mesangial cells are colocalized.

The present paper adds new findings on the nature of the mesangial cells. Based on these, we additionally seek to elucidate the features and systematics of a section of intensively studied but nevertheless confusing diversity of connective tissue cells of vertebrate organs.

Acknowledgements. We would like to express our gratitude to Prof. Dr. Wolfgang KüHnEL, Medizinische Universität zu Lübeck, and Prof. Dr. Manfred Ueck, Justus von Liebig-Universität Giessen, Germany, for their encouragement throughout the course of this work.

\section{REFERENCES}

Ausiello, D. A., J. J. Kreisberg, C. Roy and M. J. KARNOVSKY: Contraction of cultured rat glomerular mesangial cells after stimulation with angiotensin II and arginine vasopressin. J. Clin. Invest. 65: 754-760 (1980).

BrenNer, B. M., L. D.DWorkin and I. IChIKaWa: Glomerular ultrafiltration. In: (ed. by) B. M. BRENNER and F. C. RECTOR: The kidney, Vol. 2. Saunders, Berlin, 1986 (p. 124-144).

DrenckhahN, D., H. Schnittler, R. Nobiling and W. KRIZ: Ultrastructural organization of contractile proteins in rat glomerular mesangial cells. Amer. J. Pathol. 137: 1343-1351 (1990).

Fawcett, D. W.: The urinary system. In: Bloom and FAwCETT, A textbook of histology. 12th Ed. Chapman \& Hall, New York-London, 1994 (Chap. 30, p. 728-767).

Foidart, J. B. and P. Mahieu : Glomerular mesangial cell contractility in vitro is controlled by an angiotensin-prostaglandin balance. Mol. Cell Endocrinol. 47: 163-173 (1986).

Hardisty, M. W. and I. C. Potter: The general biology of adult lampreys. In: (ed. by) M. W. HARDISTY and I. C. PotTer: The biology of lampreys. Academic Press, London-New York, 1977 (p. 127-206).

Hatae, T., T. Ichimura, T. Ishida, T. Sakurai and M. FujiTa: Occurrence of unusual tubular invaginations of the plasma membrane in smooth muscle cells of the lamprey, Lampetra japonica. Cell Tiss. Res. 276: 51-59 (1994).

IsHII, T. and T. IshII: Zur Darstellung der argyrophilen Faser: Eine Modifikation der Silberimprägnationsmethode von Bielschowsky-Maresch. Mikroskopie 20: 1-11 (1965).

Johnson, R., J. Floege, A. Yoshimura, H. Iida, W. Couser and C. ALPERS: The activated mesangial cell: a glomerular "myofibroblast"? J. Amer. Soc. Nephrol. 2: S190-S197 (1992).

Komuro, T.: Re-evaluation of fibroblasts and fibroblastlike cells. Anat. Embryol. 182: 103-112 (1990). 
KREISBERG J. J.: Contractile properties of the glomerular mesangium. Fed. Proc. 42: 3053-3057 (1983).

KuPFFER, C.: Ueber Sternzellen der Leber. Arch. Mikrosk. Anat. 12: 353-358 (1876).

Kusumoto, Y. and T. Fujita: Viamin A uptake cells distributed in the liver and other organs of the rat. Arch. Histol. Jap. 40: 121-136 (1976).

Miyoshi, M.: Scanning electron microscopy of the renal corpuscle of the mesonephros in the lamprey, Entosphenus japonicus Martens. Cell Tiss. Res. 187: 105-113 (1978).

Sadovnic, M., J.Brand-ElnagGar and W. Bolton: Isolation and characterization of chicken mesangial cells. Nephron 58: 75-84 (1991).

SAKAI, T. and W. KRIZ: The structural relationship between mesangial cells and basement membrane of the renal glomerulus. Anat. Embryol. 176: 373-386 (1987).

SchlondoRFF, D.: The glomerular mesangial cell: an expanding role for a specialized pericyte. FASEB J. 1: 272-281 (1987).

W AKE, K.: Development of vitamin A-rich lipid droplets in multivesicular bodies of rat liver stellate cells. J. Cell Biol. 63: 683-691 (1974).

: Perisinusoidal stellate cells (fat-storing cells, interstitial cells, lipocytes), their related structure in and around the liver sinusoids, and vitamin A-storing cells in extrahepatic organs. Int. Rev. Cytol. 66: 303-353 (1980).

: The Sternzellen of von Kupffer-after 106 years. In: (ed. by) D. L. KNOOK and E. WISSE: Sinusoidal liver cells. Elsevier Biomedical, Amsterdam-New York-Oxford, 1982 (p. 1-12).

W AKE, K. and H. Senoo: Morphological aspects of the differentiation of stellate cell line in the vertebrates. In: (ed. by) A. KIRN, D. L. KNOOK and E. WISSE: Cells of the hepatic sinusoid. Vol. 1, Kupffer Cell Foundation, Rijswijk, The Netherlands, 1986 (p. 215-220).
W AKe, K., K. Motomatsu, H. Senoo, A. Masuda and E. ADACHI: Improved Kuppfer's gold chloride method for demonstrating the stellate cells storing retinol (vitamin A) in the liver and extrahepatic organs of vertebrates. Stain Technol. 61: 193-200 (1986).

Wake, K., K. Мотомatsu and H. Senoo: Stellate cells storing retinol in the liver of adult lamprey, Lampetra japonica. Cell. Tiss. Res. 249: 289-299 (1987).

Wake, K., T. Sato, W. Ekataksin and K. Kaneda: Pillar cells in gill filaments of the lamprey, Lampetra japonica, store retinol. Biomed. Res. 10: 597-605 (1989).

W Aldherr, R., S. Cuzic and I. Noronha: Pathology of the human mesangium in situ. Clin. Invest. 70: 865-874 (1992).

Yamada, E. and K. Hirosawa: The possible existence of a vitamin A-storing cell system. Cell Str. Funct. 1: 201204 (1976).

YamanAKA, N.: Development of the glomerular mesangium. Pediatr. Nephrol. 2: 85-91 (1988).

Youson, J. H.: The kidneys. In: (ed. by) M. W. HARDISTY and I. C. PotTer: The biology of lampreys. Vol. 3. Academic Press, London, 1981 (p. 191-261).
Peter BAUER

Institut für Anatomie

Medizinische Universität zu Lübeck

Ratzeburger Allee 160

23538 Lübeck, Germany 